\title{
Near-Surface Attenuation Modelling Based on Rock Shear-Wave Velocity Profile
}

\author{
A.M. Chandler ${ }^{1}$, N.T.K. Lam ${ }^{2}$ and H.H. Tsang ${ }^{3}$ \\ ${ }^{1}$ Professor and Director, Centre for Earthquake Engineering Research (CEER), \\ Department of Civil Engineering, University of Hong Kong, Pokfulam Road, Hong Kong \\ ${ }^{2}$ Associate Professor and Reader, Department of Civil and Environmental Engineering, \\ University of Melbourne, Parkville, Victoria 3010, Australia \\ E-mail n.lam@civenv.unimelb.edu.au ; Fax +03 83444616 (Corresponding Author) \\ ${ }^{3} \mathrm{PhD}$ Candidate, Centre for Earthquake Engineering Research (CEER), \\ Department of Civil Engineering, University of Hong Kong, Pokfulam Road, Hong Kong
}

\begin{abstract}
In a previous study published in this journal, the authors developed a comprehensive methodology for modelling the shear wave velocity profile in crustal rock, for purposes of seismic hazard assessment. The derived shear wave velocity profile was used to estimate the amplification and attenuation mechanisms in the transmission of seismic waves. The ability to conduct seismic hazard assessments in regions of low and moderate seismicity is greatly enhanced by this new modelling approach, given that developing a local attenuation model based on curve-fitting strong motion data is generally not feasible under such conditions. This paper reports a follow-up study conducted to evaluate the significance of near-surface attenuation in bedrock (as distinct from attenuation in unconsolidated soft soil sediments). The $\kappa$ parameter is used to characterize the extent of this attenuation mechanism. Empirical correlations of $\boldsymbol{k}$ with two forms of near-surface shear wave velocity parameter in crustal rock have been developed, employing information obtained from global sources in conjunction with that from local studies. The resulting development of two simple equations to predict median values of $\boldsymbol{K}$ as functions of readily available shear wave velocity parameters represents the key outcome of this study. Applications of the proposed empirical approaches to determine $\boldsymbol{\kappa}$ have been provided, taking Hong Kong and Melbourne as case studies to illustrate different aspects of the proposed methodology. Consistency between the results obtained by the two recommended approaches has thereby been demonstrated.
\end{abstract}

Keywords: $\quad$ upper-crust, near-surface attenuation, shear wave velocity, kappa 


\section{Introduction}

This study is concerned with the seismological model which comprises factors representing the effects of the source, path and site for defining the frequency contents of the earthquake. When all parameters in the seismological model have been well defined, artificial accelerograms could be simulated by means of a stochastic process. In regions with a paucity of strong motion recordings (which include regions of low and moderate seismicity), this methodology of ground motion attenuation modelling based on accelerogram simulations is an attractive alternative to conventional empirical modelling (based on the regression of recorded accelerogram data). The seismological modelling methodology was originally developed in North America and subsequently adapted to, and further developed in, Europe. The abundance of data obtained from seismographic recordings in Eastern North America (ENA) enables source and path parameters required for input into the seismological model to be ascertained. Reliable seismic hazard analyses for ENA have been successfully undertaken based on the accelerograms and the associated response spectra simulated from the modelling.

Whilst seismological modelling has been popular in the well studied regions of ENA, adapting this modelling methodology to other regions with a paucity of both accelerogram and seismographic recordings poses a major challenge due to uncertainties in the parameters values required for input into the seismological model. It has been the long-term research objectives of the author to circumvent this problem of parameter uncertainties in order that such simulation methodology can be adopted more widely.

The study reported in this paper forming part of the objective is concerned mainly with the $\kappa$ parameter (in units of seconds and pronounced " kappa") parameter which represents the near-surface attenuation (energy absorption) of upward propagating seismic waves in the upper 3-4 $\mathrm{km}$ of the earth crust. It is noted that direct measurements of $\kappa$ is not straightforward. For example, measuring $\kappa$ using the wellknown Coda-wave technique (e.g. Ref. [1]) requires placing the recording stations very close to the epicentre of the earthquakes. For this reason, database of $\kappa$ is very restrictive in the world context. 
The principal objective of this paper is to develop the correlation between $\kappa$ and parameters defining the shear wave velocity $(S W V)$ profile of the region. In a previous study published in this journal [2], the authors developed a comprehensive methodology for modelling regional $S W V$ profiles for different geological settings around the world. Combining the outcomes of the two studies (i.e. Ref. [2] and this paper) enables the $\kappa$ parameter to be estimated for regions where sufficient relevant data from direct measurements are not available.

The key relationships are presented systematically and illustrated with case studies at the end of the paper to facilitate its applications.

\section{Seismological modelling}

Regional ground motion attenuation relationships for intra-plate regions having low to moderate seismic activity rates usually cannot be developed by conventional empirical modelling, since there is typically a scarcity of strong motion accelerogram records. Nonetheless, there are alternative means by which representative seismic hazard models for these regions can be developed. For example, in countries or regions with a long history of archival records (such as China), models can be developed from databases of iso-seismal intensity maps of historical earthquakes. However, seismic hazard information that can be inferred from historical intensity data tends to be rather generalised.

Seismological modelling has been developed to provide more specific information on the predicted ground shaking through stochastic simulations. The seismic hazard obtained from the simulation methodology may then be verified by comparison with historical intensity data. This dual approach of combining the seismological model with historical intensity data has been applied by the authors in seismic hazard modelling for South China [3,4] and Australia [5].

A seismological model that could be developed from a database of seismograms (such as in Central and Eastern North America, CENA) could resolve ground shaking into its source, path and site components. Modelling for each of these components could be undertaken using a combination of a theoretical approach and empirical ground motion data. The seismological Quality Factor, $Q$, is amongst the many 
parameters required for input into the seismological model. $Q$ defines the wave transmission quality of the earth's crust in the study region. The Spectral Ratio Method and the Coda Wave Method, that are based on observing the decay of low intensity ground motion with distance (or time) [1], are amongst the methods that have been devised to conveniently measure the regional $Q$ factor. $Q$-factors for different regions within China have also been inferred from historical intensity data [6]. Using one of these techniques, $Q$ has been modelled in several regions of low and moderate seismicity.

The value of $Q$ obtained from seismological monitoring can be substituted into equation (1) to develop the filter function $\operatorname{An}(f)$ which represents the effects of whole path attenuation of seismic waves propagating within the earth's crust:

$$
A n(f)=e^{-\cdot \frac{\pi \cdot f \cdot R}{Q \cdot V_{s}}}
$$

where $f$ is the wave frequency, $R$ is the length of the wave travel path and $V_{s}$ is the $S W V$.

The filter function defined by equation (1) may be combined with other filter functions representing various source, path and site effects to predict the Fourier spectrum of seismic waves reaching the ground surface. The developed spectral information may then be used for generating artificial ground motions using stochastic simulations (as reviewed in Ref.[7]). The simulated accelerograms may then be subject to response spectrum analysis for engineering applications.

It has been found from such simulation studies [8] that regional variations in the $Q$ factor will only have engineering significance for distant earthquakes with epicentral distances exceeding around $70 \mathrm{~km}$.

In fact, the regional $Q$ factor as measured by any one of the methods described above only represents a part of the total attenuation experienced by seismic waves on reaching the ground surface. A considerable amount of attenuation is experienced during transmission through the upper layers of the earth's crust, including unconsolidated soft soil sediments. This attenuation mechanism is always accompanied by associated amplification mechanisms. Unless drill-holes have been suitably instrumented, neither of the above mechanisms can be studied by observing the decay, or amplification, 
of the seismic wave with distance, since the change in wave amplitudes occurs over very short distances within the wave transmission path. The combined attenuation-amplification effects are often treated as site effects (or soil modification effects) that could be modelled by one-dimensional shear wave analysis [9] (for example, using the well-known computer program SHAKE [10]).

It is noted that site response analyses undertaken by engineers usually only consider the wave modification properties of soil sediments overlying bedrock, and not those modifications that occur within the bedrock itself, despite the latter's significance. Importantly, wave transmission quality within bedrock is not uniform with depth. Near-surface attenuation (also known as "upper-crust" attenuation) occurs over a very short transmission distance, as for attenuation in soft soil sediments. Ref.[11] identified that $90 \%$ of the total attenuation of seismic waves in Californian bedrock occurred within the upper $4 \mathrm{~km}$ of the earth's crust. As previously mentioned, attenuation of this nature, though significant, cannot be captured by methods which are based on monitoring the decay of wave intensity with distance (for example, the Spectral Ratio Method referred to above).

A range of methods has been used to measure the near-surface attenuation properties in bedrock. However, near-surface attenuation still remains an element of uncertainty in most parts of the world, due to difficulties with its measurement as well ambiguities in the definition of the associated attenuation parameter $\kappa$ (refer Section 3 for further details). When this important mechanism has not been ascertained, a reliable seismological model for the region is difficult to develop.

The filter function, $P(f)$, that can be used to represent near-surface attenuation in the seismological model has been defined by equation $(2 \mathrm{a})$ :

$$
P(f)=e^{-. \pi f \kappa}
$$

where the parameter $\kappa$ (in units of seconds) is used to represent the combined factor $R / Q V_{s}$ in equation (1). Each of the variables in this factor has been assigned the subscript " $u c$ ", which denotes contributions by the upper crust. Thus: 


$$
\kappa=R_{u c} /\left(Q_{u c} V_{u c}\right)
$$

Given that around $90 \%$ of the crustal attenuation, defined herein as near-surface attenuation, has been found to occur in the upper $4 \mathrm{~km}$ of the earth's crust, the value of $R_{u c}$ has been taken as a constant equal to $4 \mathrm{~km}$. The value of $Q_{u c}$ represents the value of $Q$ within the upper crust and is the parameter this study aims to model. Finally, $V_{u c}$ is the average shear wave velocity ( $S W V$ ) of the upper crust (4 km depth), defined by:

$$
V_{u c}=\frac{R_{u c}}{\sum_{i} \frac{d z_{i}}{V_{s_{i}}}} \quad \text { or } \quad \frac{R_{u c}}{\int_{0}^{R_{u c}} \frac{d z}{V_{s}}}
$$

where $i$ is layer number, each having finite depth $d z_{\mathrm{i}}$.

\section{Measurement of the $\kappa$ parameter}

As mentioned in Section 2, near-surface attenuation properties of the earth's crust cannot be inferred from the rate of attenuation of ground motion amplitude with increasing epicentral distance. Thus, nearsurface effects have not been distinguished from source effects in conventional attenuation models. However, the measurement methods described in this section do enable near-surface attenuation and the associated $\kappa$ parameter to be measured.

In the method developed in Ref.[12], the Fourier transform of the recorded accelerations is first taken and plotted versus frequency using log-linear scales. Accelerograms used in conjunction with this method were typically recorded from events in the magnitude range M4-M7. The value of $\kappa$ may then be inferred from the slope of the straight-line fitted between the corner frequency (less than $5 \mathrm{~Hz}$ for $\mathrm{M}>4$ ) and the upper frequency limit (typically at $15-30 \mathrm{~Hz}$ ) of the spectrum. This method of measuring attenuation is based on the assumption that variations in the Fourier amplitude with frequency over the 
range where measurements are taken arise entirely due to attenuation. It is further noted that the method is based on a different definition of the $\kappa$ parameter, which represents the combined whole-path and near-surface attenuation effects [refer equation (4), which combines equation (1) with equation (2a)].

$$
A n(f) \cdot P(f)=e^{-\pi f \kappa}
$$

where

$$
\kappa=\frac{R}{Q V_{s}}+\kappa_{o}
$$

In equation ( $4 \mathrm{~b}), \kappa_{o}$ could be obtained by extrapolating the linear trend of $\kappa$ versus epicentral distance to "zero" epicentral distance [12]. In this paper, both parameters $\kappa$ and $\kappa_{o}$, which may be used interchangeably, represent solely the near-surface attenuation [despite that $\kappa$ is defined differently in equation (4b)]. Using this method, a $\kappa\left(\right.$ or $\left.\kappa_{o}\right)$ value equal to $0.04 \mathrm{~s}$ has been identified for California [12], $\kappa=0.07 \mathrm{~s}$ for the southern and central Apennines in Italy [13] and $\kappa=0.011 \mathrm{~s}$ in British Columbia [14].

In an alternative method of determining the $\kappa$ parameter, a seismological model that has resolved nearsurface effects into numerous attenuation and amplification components was first developed [15]. Fourier spectra simulated from the seismological model assuming a range of trial values of $\kappa$ were then compared with the spectrum determined from the recorded ground motion, in order to identify the "best matched" spectra. This method of matching spectra, which is distinguished from the method in Ref.[12], addresses frequency dependent amplification of the seismic waves which co-exist with attenuation. However, non-unique estimates of $\kappa$ are produced, as the estimated $\kappa$ value would depend on the frequency functions that have been incorporated into the seismological model. This method of measurement, which was adopted in Ref's [15] and [16], predicts higher $\kappa$ than those determined by the original method introduced in Ref.[12]. However, the discrepancy is generally rather small (only $0.006 \mathrm{~s}$ in the case of California, for example). 
There also exists significant trading-off between $\kappa$ and the assumed stress-drop level. Stress-drop varying between 30 bars and 600 bars has been assumed in Ref's [16]-[19], for different regions within Italy and Europe. Considerable uncertainties in the actual $\kappa$ value have been associated with such estimates, because of the stress-drop variability. In a study for Switzerland [20], $\kappa=0.015 \mathrm{~s}$ was recommended based on the very low stress-drop level of 5-10 bars. A significantly higher $\kappa$ value would have been estimated had the modelled stress drop level been increased. In Ref.[21], $\kappa=0.04 \mathrm{~s}$ was recommended for Central Mexico, but details of the measurements have not been reported. Neither of these studies has been included in the listing given herein in Table 1.

Estimates of $\kappa$ have also been proposed for other parts of the world in studies including Ref's [22]-[25], but the recommendations were based only on measurements reported elsewhere. These references have similarly not been included in Table 1. References [26] and [27] have also not been enlisted (due to insufficient information to complete all column entries in the table).

The $\kappa$ parameter could alternatively be determined by observing the decay of the Coda wave envelope with time [28], but the observations must be made at shallow depths and very close to the epicentre of the earthquake, in order that only a small volume of the earth's crust close to the surface (within the upper $4 \mathrm{~km}$ ) is included in the measurement. The value of $\kappa$, or the Quality factor of the upper crust, $Q_{u c}$, can be calculated from the ratio of the envelope amplitude observed for a range of specified frequencies. Recordings close to the earthquake epicentre are scarce in low and moderate seismic regions, but earthquake swarms offer excellent opportunities for this type of measurement.

It is evident from the above review and discussion that it is generally difficult to measure $\kappa$ in low and moderate seismic regions, where recordings from local moderate and large magnitude earthquakes in the near field are either non-existent or, at best, scarce. It is proposed that the value of $\kappa$ be estimated instead in accordance with its correlation with parameters that can be identified most easily from normal engineering investigations. For example, near-surface $S W V$ can be inferred from shallow drill-hole records and hence is generally available. Such correlations will be developed in Section 4 . 


\section{Correlations of $\boldsymbol{K}$ with shear wave velocity parameters}

Correlations between $\kappa$ and shear wave velocity parameters cannot be obtained directly from existing field data. In developing these relationships, the following steps were undertaken:

(i) Correlating $Q_{u c}$ with $Q_{0}$ (refer Section 4.1)

(ii) Correlating $Q_{0}$ with $S W V$ parameters: $V_{u c}$ and $V_{s, 0.03}$ (refer Section 4.2)

(iii) Combining correlations obtained from steps (i) and (ii) to obtain correlation of $\kappa$ with $V_{u c}$ and $V_{s, 0.03}($ refer Section 4.3).

It is emphasized that the shear wave velocity parameter $\left(V_{u c}\right.$ or $\left.V_{s, 0.03}\right)$ is based on the average conditions of an area and is not intended to represent specific sites. Hence, it is compatible to the database of $\kappa$ and $Q$ parameters used in this study.

\subsection{Correlation of $Q_{u c}$ with $Q_{0}$}

First, incorporated into Table 1 are the recommendations by a number of the seismological investigations reviewed in Section 3. For each of the studies listed in Table 1, the value of $Q_{u c}$ was calculated using equation (2b), based on the tabulated value of $\kappa$ (refer Column 2). Further, $V_{u c}$ was determined from equation (3) (with the $S W V$ profile defined by the functional form developed in Ref.[2] along with the parameters provided by the CRUST2.0 global crustal model [29]). A constant value of $R_{u c}(=4 \mathrm{~km})$ was assumed. Also given in Table 1 is the $Q_{0}$ value, which has been determined for the same region. The ratio of $Q_{u c} / Q_{0}$ inferred from the different studies is shown to have a median value of around 0.2. However, as a result of different modelling assumptions there exists considerable scatter in the individual estimates that vary from this median value by up to around $50 \%$. Thus, developing a rigorous model for defining the ratio for $Q_{u c} / Q_{0}$ is not considered justified. Instead, a constant ratio of $Q_{u c} / Q_{0}=0.2$ has been assumed herein.

It was found from seismological studies conducted in southeastern Australia [28], based on the measurement of Coda wave envelopes, that the value of $Q_{u c}$ is some $20 \%$ of the value of $Q_{0}$, which is consistent with the trend revealed in Table 1. Further verification of this ratio has been provided in the later part of this paper. 
The $Q_{u c} / Q_{0}$ ratio as obtained from this section enables estimates to be made of $Q_{u c}$, assuming that information on the value of $Q_{0}$ is available (refer Section 4.3).

\subsection{Correlation of $Q_{0}$ with shear wave velocity}

Second, published values were collated for the regional seismological Quality factor $Q\left(=Q_{0}\right.$ at frequency of $1 \mathrm{~Hz}$ ). The Quality factor $Q$, compared with $\kappa$, is a more commonly known parameter in different regions around the world. The databases that have been sourced include Ref's [6-8,13,16,17,25,30]. For each region from which the $Q$ value was reported, the corresponding value of the average $S W V V_{u c}$ of the upper crust (taken herein as the upper $4 \mathrm{~km}$ depth) was identified using data from the global crustal model CRUST2.0 [29], developed originally in Ref.[31]. The correlation between $Q_{0}$ and $V_{u c}$ so obtained from the survey has been shown in Figure 1a and Table 2, and represented mathematically by equation (5a):

$$
Q_{0}=100+2.5 V_{u c}^{4.5} \quad\left[V_{u c} \geq 1.6 \mathrm{~km} / \mathrm{s}\right]
$$

Generally, the sedimentary crustal rock is assumed deposited continuously in different geological periods. According to Ref.[2], the $S W V$ profile within the crustal layer can (with some exceptions, refer below) be modelled by a generic functional form. Hence, it is possible to deduce the expected nearsurface $S$-wave velocity, based on a given value of $V_{u c}$. The $S$-wave velocity at a shallow reference depth of $0.03 \mathrm{~km}(30 \mathrm{~m})$, termed $V_{s, 0.03}$, is proposed as the key parameter in the following derivation. The parameter $V_{s, 0.03}$ provides a logical approach to characterizing the overall hardness of the upper-crust, in situations where the associated parameter $V_{u c}$ for the full $S W V$ profile (upper $4 \mathrm{~km}$ ) cannot easily be obtained.

On the above basis, the correlation between $Q_{0}$ and $V_{s, 0.03}$ can be deduced, as shown in Figure $1 \mathrm{~b}$ and Table 2 , and represented mathematically by equation $(5 \mathrm{~b})$. It is noted that the shallow-depth rock velocity parameter $V_{s, 0.03}$ is linked directly to the common practice in existing seismic design codes, whereby sites are characterised by their $S W V$ in the upper $30 \mathrm{~m}$. Furthermore, $V_{s, 0.03}$ is of particular engineering interest as it can be readily obtained from engineering boreholes and normal site investigation. 
Nevertheless, other depth values could be employed to serve this purpose, according to the methodology described in Ref.[2].

$$
Q_{0}=60+320\left(V_{s, 0.03}-0.5\right)^{0.8} \quad\left[0.5 \mathrm{~km} / \mathrm{s} \leq V_{s, 0.03} \leq 3.0 \mathrm{~km} / \mathrm{s}\right]
$$

It is noted that some exceptional conditions, for which the aforementioned assumption linking $V_{s, 0.03}$ directly with $V_{u c}$ is invalid, do exist. Ref.[4] provides information on such an example, using Hong Kong as the case study.

It is noted that the value of $Q$ obtained from seismological monitoring depends on the modelling assumptions adopted in each individual study. For example, there is some trading-off between geometrical and anelastic attenuation (with the latter represented by the $Q$-factor). Thus, varying assumptions with regard to the geometrical attenuation would result in different anelastic attenuation, and hence the $Q$-factor. Furthermore, the epicentral distances and direction of the wave transmission path in the monitored earthquakes would also affect the $Q$ values being reported. It is noted that $Q$ has been obtained from a multiplicity of studies employing different methodologies. Consequently, there exists considerable scatter in the correlations presented in Figures 1a and 1b. Even with these measurement uncertainties, the close link between regional transmission quality of the rock and the $S W V$ (i.e. $Q_{0}$ versus $V_{u c}$ or $\left.V_{s, 0.03}\right)$ is evident.

The values of $V_{u c}$ and $V_{s, 0.03}$ are also subject to considerable uncertainty. The value as inferred from the global crustal model [29] can be checked by comparison with local measurements. However, note that values of $V_{u c}$ and $V_{s, 0.03}$ are subject to significant variations between different sites within the same region. Thus, a representative sample of local measurements would have to be collected, and averaged, in order for a regional measured value to be obtained.

\subsection{Correlation of $\kappa$ with shear wave velocity}

Third, and finally, the correlation adopted for modelling $Q_{0}$ is now extended to the modelling of $Q_{u c}$ and $\kappa$. The purpose is to enable the upper-crust attenuation property to be linked directly to the upper-crust structure (characterized by $V_{u c}$ ) and a commonly determined engineering parameter, namely $V_{s, 0.03}$. 
The median $Q_{u c} / Q_{0}$ ratio of 0.2 was applied to each of the regions from which the data in Figures 1 a and $1 \mathrm{~b}$ was plotted. In each case, the value of $Q_{u c}, V_{u c}$ and $R_{u c}(=4 \mathrm{~km})$ was identified for substitution into equation (2b), in order that $\kappa$ could be evaluated along with the value of $Q_{0}$ that was known originally. A new array of $\kappa$ values was then created for correlation with the $V_{u c}$ and the $V_{s, 0.03}$ arrays, respectively, as shown in Figures $2 \mathrm{a}$ and $2 \mathrm{~b}$ and Table 2, and represented mathematically by equations (6a) and (6b):

$$
\begin{array}{cc}
\kappa=0.145-0.12 \ln \left(V_{u c}\right) \geq 0 & {\left[V_{u c} \geq 1.6 \mathrm{~km} / \mathrm{s}\right]} \\
\kappa=\frac{0.057}{V_{s, 0.03}^{0.8}}-0.02 & {\left[0.5 \mathrm{~km} / \mathrm{s} \leq V_{s, 0.03} \leq 3.0 \mathrm{~km} / \mathrm{s}\right]}
\end{array}
$$

The median predictions for $\kappa$, given by equations (6a) and (6b) and based on Figures $2 \mathrm{a}$ and $2 \mathrm{~b}$, are the key outcome of this research investigation and can be further supported by numerous studies, as reported in Ref's $[8,13,15,16,23,25,32,33]$. The observed scatter ultimately is due to the fact that the crustal $S W V$ profile can vary significantly, even with a uniform value of $V_{u c}$ or $V_{s, 0.03}$. Furthermore, influence by parameters that affect crustal damping properties could also contribute to the scatter. It is evident that scatter would be much smaller with a model that has incorporated a larger number of such parameters. However, if the model is to be of practical engineering value, information on the parameters must be readily available before being included in the modelling. It is noted that at the present time, $V_{s, 0.03}$ [equation (6b)] is much more straightforward to obtain than other parameters, in the context of normal engineering practice.

By combining equations (2b) and (5a) and making comparisons with equation (6a), the $Q_{u c} / Q_{0}$ ratio can be inferred. It is found that the ratio is in the range $0.18-0.23$, for the normal range $1.6 \mathrm{~km} / \mathrm{s} \leq V_{u c} \leq 3.0$ $\mathrm{km} / \mathrm{s}$, and on this basis the assumption for typical $Q_{u c} / Q_{0}$ ratio $(=0.2)$ has been reaffirmed. It is also expected that for $V_{u c} \geq 3.0 \mathrm{~km} / \mathrm{s}$, the ratio would be larger than 0.2 , based on the physical property that the upper-crust material is (for that case) not significantly softer than that at mid-crust.

Finally, with regard to the velocity parameter $V_{s, 0.03}$, if consideration is given to the $S W V$ relationship established in Ref.[2] for the Upper Sedimentary Layer, it may be shown that the $S W V$ averaged over the upper $0.03 \mathrm{~km}(30 \mathrm{~m})$ rock layers is in the order of $0.75 V_{s, 0.03}$. As it is common practice in existing 
seismic codes of practice to use such average velocity to define the soil or rock class, a useful alternative formulation is to replace $V_{s, 0.03}$ in equation (6b) by 1.33 times the velocity averaged over the upper $30 \mathrm{~m}$ depth in rock.

The procedure used for determining the $\kappa$ parameter using relationships developed in this Section is summarised below:

1) Construct a representative $S W V$ profile for the region, or area, based on global information in conjunction with that from local studies.

2) Identify the $S W V$ parameter $V_{s, 0.03}$ and/or $V_{u c}$, and use equation (6a) or (6b) as appropriate to determine $\kappa$.

3) Supplementary (optional) calculations can be used to check with the estimates obtained from equation (6). This calculation requires a representative whole-path attenuation Quality Factor $(Q)$ to be identified from reliable local seismological studies [not from equation (5)]. Equation (2b) is then used to determine an alternative estimate for $\kappa$, assuming $Q_{u c}=0.2 Q$.

\section{Applications of proposed methodology for determining the $\boldsymbol{\kappa}$ parameter}

\subsection{Hong Kong, South China}

As the sedimentary crustal rock in Hong Kong was not deposited continuously over different geological periods (Ref.[4]), it is unreliable to infer crustal attenuation properties from $S W V$ near the earth surface. Thus, equation (6a) based on the average $S W V V_{u c}$ of the upper crust was used in the estimation of $\kappa$. The proposed procedure requires availability of the entire $S W V$ profile up to $4 \mathrm{~km}$ depth, in order to evaluate $V_{u c}$ using equation (4).

$S W V$ profiles for Hong Kong (to crustal depths exceeding $8 \mathrm{~km}$ ) have been developed by the authors in Ref.[4]. The referred study demonstrated the use of $S W V$ information obtained from a combination of sources to constrain the model $S W V$ profiles for four principal geological formations in Hong Kong: (i) 
granitic formation, (ii) volcanic formation, (iii) heavily-jointed volcanic formation, and (iv) metasedimentary formation. The $S W V$ profile information for each of these common geological formations were obtained as follows: a) at shallow depths from instrumented boreholes (e.g. Ref's [34-36]); b) at depths of up to 100-500 m from Spectral Auto-Correlation (SPAC) measurements (Ref's [37-38]); c) at depths up to $1.5 \mathrm{~km}$ from the monitoring of quarry blasts (Ref.[39]); and d) at depths $1.5-8 \mathrm{~km}$ in the hard (crystalline) basement rock layers from results of seismological refraction surveys as reported on the global database CRUST2.0 (Ref.[29]).

In addition to the four prevalent geological formations, a regional average profile for Hong Kong has also been proposed (Ref.[4]). The regional average profile has been determined by assigning an appropriate set of weightings to different geological formations in Hong Kong (based mainly on their relative frequency of occurrence in the Territory). The assumed weightings are $0.4,0.35,0.2$ and 0.05 , for granitic, volcanic, heavily-jointed volcanic and meta-sedimentary rocks, respectively. The profiles for different types of rocks and the regional average profile are shown in Figure 3 and are mathematically presented by equations (7a-7e).

Granitic formation:

$$
\left.\begin{array}{ll}
V_{s}(Z)=1350\left(\frac{Z}{30}\right)^{\frac{1}{4}} \mathrm{~m} / \mathrm{s} & Z<120 \mathrm{~m} \\
V_{s}(Z)=1900 \mathrm{~m} / \mathrm{s} & 120<Z<500 \mathrm{~m} \\
V_{s}(Z)=2150 \mathrm{~m} / \mathrm{s} & 500<Z<1000 \mathrm{~m} \\
V_{s}(Z)=2160 \mathrm{~m} / \mathrm{s} & 1000<Z<1500 \mathrm{~m} \\
V_{s}(Z)=3300\left(\frac{Z}{4000}\right)^{\frac{1}{6}} \mathrm{~m} / \mathrm{s} & 1500<Z<4000 \mathrm{~m}
\end{array}\right\}
$$

Volcanic formation:

$$
\left.\begin{array}{ll}
V_{s}(Z)=2200\left(\frac{Z}{30}\right)^{\frac{1}{4}} \mathrm{~m} / \mathrm{s} & Z<32 \mathrm{~m} \\
V_{s}(Z)=2240 \mathrm{~m} / \mathrm{s} & 32<Z<500 \mathrm{~m} \\
V_{s}(Z)=2390 \mathrm{~m} / \mathrm{s} & 500<Z<1000 \mathrm{~m} \\
V_{s}(Z)=2330 \mathrm{~m} / \mathrm{s} & 1000<Z<1500 \mathrm{~m} \\
V_{s}(Z)=3300\left(\frac{Z}{4000}\right)^{\frac{1}{6}} \mathrm{~m} / \mathrm{s} & 1500<\mathrm{Z}<4000 \mathrm{~m}
\end{array}\right\}
$$


Heavily-Jointed Volcanic formation:

$$
\begin{array}{ll}
V_{s}(Z)=1600\left(\frac{Z}{30}\right)^{\frac{1}{4}} \mathrm{~m} / \mathrm{s} & Z<48 \mathrm{~m} \\
V_{s}(Z)=1800 \mathrm{~m} / \mathrm{s} & 48<Z<500 \mathrm{~m} \\
V_{s}(Z)=1820 \mathrm{~m} / \mathrm{s} & 500<Z<1000 \mathrm{~m} \\
V_{s}(Z)=2120 \mathrm{~m} / \mathrm{s} & 1000<Z<1500 \mathrm{~m} \\
V_{s}(Z)=3300\left(\frac{Z}{4000}\right)^{\frac{1}{6}} \mathrm{~m} / \mathrm{s} & 1500<\mathrm{Z}<4000 \mathrm{~m}
\end{array}
$$

$V_{s}(Z)=1150\left(\frac{Z}{6}\right)^{\frac{1}{4}} \mathrm{~m} / \mathrm{s}$

$V_{s}(Z)=1150 \mathrm{~m} / \mathrm{s}$

$V_{s}(Z)=1250 \mathrm{~m} / \mathrm{s}$

$V_{s}(Z)=1350 \mathrm{~m} / \mathrm{s}$

$V_{s}(Z)=2100 \mathrm{~m} / \mathrm{s}$

$V_{s}(Z)=3300\left(\frac{Z}{4000}\right)^{\frac{1}{6}} \mathrm{~m} / \mathrm{s}$

$V_{s}(Z)=1700\left(\frac{Z}{30}\right)^{\frac{1}{4}} \mathrm{~m} / \mathrm{s}$

$V_{s}(Z)=2000 \mathrm{~m} / \mathrm{s}$

$V_{s}(Z)=2200 \mathrm{~m} / \mathrm{s}$

$V_{s}(Z)=3300\left(\frac{Z}{4000}\right)^{\frac{1}{6}} \mathrm{~m} / \mathrm{s}$
$Z<60 \mathrm{~m}$

$Z<6 \mathrm{~m}$

$6<Z<30 \mathrm{~m}$

$30<Z<100 \mathrm{~m}$

$100<Z<500 \mathrm{~m}$

$500<Z<1500 \mathrm{~m}$

$1500<Z<4000 \mathrm{~m}$

(7d)

(7e)

The values of $\kappa$ (in units of s) obtained from equation (6a) for the granitic, volcanic, heavily-jointed volcanic, meta-sedimentary formations and the regional average are, respectively, 0.032, 0.024, 0.036, 0.040 and 0.030 (as listed in Table 3). If the above-stated weightings are applied to these $\kappa$ values, a consistent regional average value of $0.030 \mathrm{~s}$ is obtained.

Supplementary calculations have been made, to check with the estimates obtained from the above procedure. First, the whole path attenuation Quality Factor $Q$ was identified to be 256 at $1 \mathrm{~Hz}$ frequency 
(i.e. $Q_{0}=256$ ) from a previous study based on monitoring of Coda waves in the Hong Kong region [1].

The regional median quality factor for the upper crust $Q_{u c}$ was then taken as 50 (being 0.2 times 256). The regional average value of $\kappa$ was then estimated at $0.030 \mathrm{~s}$, using equation (2b) based on $R_{u c}$ equal to $4 \mathrm{~km}$ and $V_{u c}$ equal to $2.62 \mathrm{~km} / \mathrm{s}$ (refer Table 3 ).

\subsection{Melbourne Metropolitan Region, Australia}

For those regions where complete $S W V$ profiles for the upper $4 \mathrm{~km}$ are not readily available and hence the associated parameter $V_{u c}$ cannot easily be obtained, equation (6b) may be employed to estimate $\kappa$, based on the near-surface $S W V$ at $30 \mathrm{~m}$ depth. For example, measurements of $S W V$ up to a depth of 120 $\mathrm{m}$ have been obtained from a series of SPAC surveys conducted in various places in the Melbourne Metropolitan Region, SE Australia (Ref.[40]), and the results are plotted in Figure 4. Regression analyses have been carried out to determine the representative (median) value of $V_{s, 0.03}$, which is equal to $1.1 \mathrm{~km} / \mathrm{s}$. The resulting value of $\kappa$ obtained from equation (6b) is $0.033 \mathrm{~s}$ (refer Table 4) (Ref.[41]).

In Melbourne, the sedimentary crustal rock can be assumed to be deposited continuously in different geological periods (Ref.[40]). Hence, the entire $S W V$ profile within the upper crustal layer can be modelled by a generic functional form according to Ref.[2], extended from the near-surface $S$-wave velocity, based on the value of $V_{s, 0.03}$. The profile is shown in Figure 4 (denoted as "Extended Model") and can be mathematically presented by equations (8a)-(8b). Undoubtedly, the extended $S W V$ profile is subject to considerable uncertainty; yet, the profile can be reasonably supported by data from the global database CRUST2.0 [29] and an independent study in Ref.[42]. Once the extended full $S W V$ profile is obtained, $V_{u c}$ can be obtained by equation (4). Subsequently, equation (6a) is employed to provide an estimate of $\kappa$. Refer Table 4, which shows $\kappa=0.027 \mathrm{~s}$ based on this calculation.

Melbourne:

$$
\begin{array}{ll}
V_{s}(Z)=1100\left(\frac{Z}{30}\right)^{\frac{1}{4}} \mathrm{~m} / \mathrm{s} & Z<500 \mathrm{~m} \\
V_{s}(Z)=3304\left(\frac{Z}{4000}\right)^{\frac{1}{6}} \mathrm{~m} / \mathrm{s} & 500<Z<4000 \mathrm{~m}
\end{array}
$$


Even with such limited data, the difference between the two estimations of $\kappa$ is less than $20 \%$, which is encouraging. Given the highly complex nature of the earth's crustal structure, the results further reaffirm the reliability of the generalised $S W V$ modelling methodology proposed by the authors in Ref.[2]. Also, the consistency of the two empirical correlations [refer equations (6a) and (6b)] between near-surface attenuation and two different measures of bedrock $S W V$ has been satisfactorily verified.

In view of uncertainties over the value of the whole path attenuation Quality Factor $(Q)$ in the Melbourne region, no supplementary calculations (as done in the Hong Kong case study) were undertaken.

\section{Conclusions}

(a) The significance of near-surface attenuation in bedrock has been identified.

(b) The $\kappa$ parameter, which characterizes the extent of near-surface attenuation, is generally difficult to measure in regions of low and moderate seismicity because of magnitude or epicentral distance requirements associated with the measurements. The value of this parameter is non-unique and is dependent on the trading-off of the attenuation factor with other factors in the seismological model. The observed variability in the $\kappa$ value reported from the different studies is caused partly by these modelling uncertainties.

(c) It was inferred from limited published information on measured $\kappa$ values that the quality factor representing upper-crust transmission $\left(Q_{u c}\right)$ was on average about 0.2 times the quality factor representing whole-path transmission $\left(Q_{0}\right)$.

(d) An empirical correlation of the whole-path attenuation parameter $Q$ (or $Q_{0}$ ) with the rock $S W V$ was first developed by collating published information. This correlation was extended to the modelling of $\kappa$ using equation (2b) and assuming that $Q_{u c} / Q_{0}$ is typically in the order of 0.2 . This ratio has also been verified using the proposed correlations between $\kappa$ and two key measures of rock $S W V$ profile in the upper crust. The median predictions for $\kappa$ given in equations (6a) and (6b) based, respectively, on correlations shown in Figures $2 \mathrm{a}$ and $2 \mathrm{~b}$ represent the key outcomes of this study. 
(e) Supplementary (optional) calculations can be used to check against the estimates obtained from equations $(6 a)-(6 b)$. This calculation requires a representative whole-path attenuation Quality Factor $(Q)$ to be identified from reliable local seismological studies. Equation (2b) is then used to determine $\kappa$, assuming $Q_{u c}=0.2 Q$.

(f) The $\kappa-S W V$ correlation relationships recommended in this paper [equations (6a) and (6b)] have thereby been reaffirmed by two example applications (for Hong Kong and Melbourne Metropolitan Region, Australia). These case studies have provided support for the developed empirical correlations, as well as demonstrating the differences in their application depending on the form of the $S W V$ profile for a given region.

\section{Acknowledgements}

This paper forms part of the outcome of major strategic research programmes undertaken by the Centre for Earthquake Engineering Research (CEER) at the University of Hong Kong in collaboration with the University of Melbourne to address seismic risk in low and moderate seismic regions worldwide. The work described in this paper was substantially supported by a grant from the Research Grants Council of the Hong Kong Special Administrative Region, China (Project No. HKU 7004/02E), whose support is gratefully acknowledged. The Australian programme has been undertaken at the University of Melbourne since 1993, and has received continuous funding from the Australian Commonwealth government. Contributions by Trevor Allen from Geoscience Australia, Canberra through recent discussions are specifically acknowledged. The authors are also very grateful to the invaluable advice given by internationally renowned experts on this subject including Prof. GF Panza from Italy; Euan Smith, David Dowrick and Peter Davenport from New Zealand; Prof. Michael Asten at Monash University and Gary Gibson at the Seismology Research Centre, Melbourne. Support over the years by A/Prof. John Wilson and Prof. Graham Hutchinson at the University of Melbourne is also acknowledged.

\section{References}

1. Mak S, Chan LS, Chandler AM, Koo RCH. Coda Q estimates in the Hong Kong region. Journal of Asian Earth Sciences2004;24(1):127-136.

2. Chandler AM, Lam NTK, Tsang HH. Shear wave velocity modelling in crustal rock for seismic hazard analysis. Soil Dynamics \& Earthquake Engineering 2005;25(2):167-185.

3. Chandler AM, Lam NTK. Intensity attenuation relationship for the south China region and comparison with the component attenuation model. Journal of Asian Earth Sciences 2002;20(7):775-790.

4. Chandler AM, Lam NTK, Tsang HH. Regional and local factors in attenuation modelling: Hong Kong case study. Journal of Asian Earth Sciences 2005; in press. 
5. Lam NTK, Sinadinovski C, Koo RCH, Wilson JL. Peak ground velocity modelling for Australian earthquakes. Journal of Seismology and Earthquake Engineering 2003;5(2):11-22.

6. Chen P, Nuttli OW. Estimates of magnitudes and short-period wave attenuation of Chinese earthquakes from modified Mercalli intensity data. Bulletin of the Seismological Society of America 1984;74(3):957-968.

7. Lam NTK, Wilson JL, Hutchinson G. Generation of synthetic earthquake accelerograms using seismological modelling: a review. Journal of Earthquake Engineering 2000;4(3):321-354.

8. Chandler AM, Lam NTK. An attenuation model for distant earthquakes. Earthquake Engineering and Structural Dynamics 2004;33(2):183-210.

9. Kramer SL. Geotechnical earthquake engineering. Prentice Hall, Upper Saddle River, New Jersey, 1996.

10. Schnabel PB, Lysmer J, Seed HB. A computer program for earthquake response analysis of horizontally layered sites. Earthquake Engineering Research Centre report: EERC 72-12, University of California at Berkeley, U.S.A., 1972.

11. Abercrombie RE. Near-surface attenuation and site effects from comparison of surface and deep borehole recordings. Bulletin of the Seismological Society of America 1997;87(3):731-744.

12. Anderson JG, Hough SE. A model for the shape of the Fourier amplitude spectrum of acceleration at high frequencies. Bulletin of the Seismological Society of America 1984;74(5):1969-1993.

13. Rovelli A, Bonamassa O, Cocco M, Di Bona M, Mazza S. Scaling laws and spectral parameters of the ground motion in active extensional areas in Italy. Bulletin of the Seismological Society of America 1988;78(2):530-560.

14. Atkinson GM. The high-frequency shape of the source spectrum for earthquakes in eastern and western Canada. Bulletin of the Seismological Society of America 1996;86(1A):106-112.

15. Boore DM, Joyner WB. Site amplification for generic rock sites. Bulletin of the Seismological Society of America 1997;87(2):327-341.

16. Malagnini L, Akinci A, Herrmann RB, Alessandro Pino N, Scognamiglio L. Characteristics of the ground motion in northeastern Italy. Bulletin of the Seismological Society of America 2002;92(6):21862204.

17. Malagnini L, Herrmann RB. Ground-motion scaling in the region of the 1997 Umbria-Marche earthquake (Italy). Bulletin of the Seismological Society of America 2000:90(4):1041-1051.

18. Malagnini L, Herrmann RB, Di Bona M. Ground-motion scaling in the Apennines (Italy). Bulletin of the Seismological Society of America 2000:90(4):1062-1081.

19. Malagnini L, Herrmann RB, Koch K. Regional ground-motion scaling in central Europe. Bulletin of the Seismological Society of America 2000;90(4):1052-1061.

20. Bay F, Fäh D, Malagnini L, Giardini D. Spectral shear-wave ground-motion scaling in Switzerland. Bulletin of the Seismological Society of America 2003;93(1):414-429.

21. Ortega R, Herrmann RB, Quintanar L. Earthquake ground-motion scaling in central Mexico between 0.7 and $7 \mathrm{~Hz}$. Bulletin of the Seismological Society of America 2003;93(1):397-413.

22. Beresnev IA, Atkinson GM. Source parameters of earthquakes in eastern and western North America based on finite-fault modelling. Bulletin of the Seismological Society of America 2002;92(2):695-710.

23. Boatwright J, Choy GL, Seekins LC. Regional estimates of radiated seismic energy. Bulletin of the Seismological Society of America 2002;92(4):1241-1255.

24. Chen S, Atkinson GM. Global comparisons of earthquake source spectra. Bulletin of the Seismological Society of America 2002;92(3):885-895.

25. Raoof M, Herrmann RB, Malagnini L. Attenuation and excitation of three-component ground motion in southern California. Bulletin of the Seismological Society of America 1999;89(4):888-902. 
26. Akinci A, Malagnini L, Herrmann RB, Alessandro Pino N, Scognamiglio L, Eyidogan H. Highfrequency ground-motion in the Erzincan region, Turkey: inferences from small earthquakes. Bulletin of the Seismological Society of America 2001;91(6):1446-1455.

27. Singh SK, Bansal BK, Bhattacharya SN, Pacheco JF, Dattatrayam RS, Ordaz M, Suresh G, Kamal, Hough SE. Estimation of ground motion for Bhuj (26 January 2001; $\mathbf{M}_{\mathrm{w}}$ 7.6) and for future earthquakes in India. Bulletin of the Seismological Society of America 2003;93(1):353-370.

28. Wilkie J, Gibson G. Estimation of seismic quality factor Q for Victoria, Australia. Journal of Australian Geology and Geophysics 1995;15(4):511-517.

29. Global Crustal Model CRUST2.0. Institute of Geophysics and Planetary Physics, The University of California, San Diego, 2001. Website: http://mahi.ucsd.edu/Gabi/rem.dir/crust/crust2.html.

30. Jin A, Aki K. Spatial and temporal correlation between coda Q and seismicity in China. Bulletin of the Seismological Society of America 1988;78(2):741-769.

31. Mooney WD, Laske G, Masters TG. CRUST 5.1: a global crustal model at $5^{\circ} \times 5^{\circ}$. Journal of Geophysical Research 1998;103(B1):727-747.

32. Frankel A, Mueller C, Barnhard T, Perkins D, Leyendecker E, Dickman N, Hanson S, Hopper M. National seismic hazard maps, June 1996. U.S. Geol. Surv. Open-File Rept. 1996:96-532.

33. Margaris BN, Hatzidimitriou PM. Source spectral scaling and stress release estimates using strongmotion records in Greece. Bulletin of the Seismological Society of America 2002;92(3):1040-1059.

34. Arup. Kowloon Canton Railway Corporation (KCRC) West Rail Contract No.: TS-500 Full scale deep foundation load testing programme, (1) Milestone 12: test pile TSW1 - Interpretative Report (Revision A), (2) Milestone 12: test pile TSW2 - Interpretative Report (Revision A), (3) Milestone 12: test pile TWW1 - Interpretative Report (Revision A), (4) Milestone 12: test pile TMC1 - Interpretative Report (Revision A) and (5) Milestone 12: test pile TMN1 - Interpretative Report (Revision A), August 1999.

35. Electronic and Geophysical Services (EGS) Asia Limited. Ground investigation term contract for geotechnical studies 1999-2001 HKHA Contract No. 144 of 1998 Works Order No. 135 Borehole geophysical survey to Fanling area 36, Phase 3 and 4, final report, April 2001.

36. Halcrow. Additional site reconnaissance and ground investigation factual report - Volume 3: Civil Engineering Department Consultancy Agreement No. CE42/98 Natural terrain hazard and risk area studies Mount Johnston North and Tung Chung East, August 1999, Halcrow Asia Partnership Limited.

37. Aki K. Space and time spectra of stationary stochastic waves, with special reference to microtremors. Bulletin of the Earthquake Research Institute 1957;35:415-456.

38. Asten M, Lam NTK, Gibson G, Wilson JL. Microtremor survey design optimized for application to site amplification and resonance modelling. Proceedings of a Conference of the Australian Earthquake Engineering Society (AEES), Adelaide, 2002.

39. Mak S. Seismic analysis for the South China region. MPhil Thesis, Department of Earth Sciences, The University of Hong Kong, 2005.

40. Roberts J, Asten MW, Tsang HH, Venkatesan S, Lam NTK. Shear wave velocity profiling in Melbourne Silurian mudstone using the SPAC method. Australian Earthquake Engineering in the New Millennium, Proceedings of a Conference of the Australian Earthquake Engineering Society (AEES), Mount Gambier, South Australia, 2004.

41. Lam N, Asten M, Chandler A, Tsang HH, Venkatesan S, Wilson J. Seismic attenuation modelling for Melbourne based on the SPAC-CAM procedure. Australian Earthquake Engineering in the New Millennium, Proceedings of a Conference of the Australian Earthquake Engineering Society (AEES), Mount Gambier, South Australia, 2004.

42. Wesson V. Seismic modelling of the Victorian lithosphere, MAppSc Thesis, Phillip Institute of Technology, Victoria, Australia, 1988. 
Table 1: Published values of $\kappa$ and $Q_{0}$, and the implied values of $Q_{u c}$ and $Q_{u c} / Q_{0}$ ratio.

\begin{tabular}{ccccccc}
\hline & $\begin{array}{c}\text { Published } \\
\kappa(\mathrm{s})\end{array}$ & $\begin{array}{c}\text { Published } \\
Q_{0}\end{array}$ & $\begin{array}{c}\text { Assumed } \\
R_{u c}(\mathrm{~km})\end{array}$ & $\begin{array}{c}\text { Assumed } \\
V_{u c}(\mathrm{~km} / \mathrm{s})\end{array}$ & $\begin{array}{c}\text { Implied } \\
Q_{u c}\end{array}$ & $\begin{array}{c}\text { Implied } \\
Q_{u c} / Q_{0}\end{array}$ \\
\hline $\begin{array}{c}\text { Central and Southern } \\
\text { Apennines, Italy [13] }\end{array}$ & 0.070 & 100 & 4 & 2.3 & 25 & 0.25 \\
Northeastern Italy [16] & 0.045 & 260 & 4 & 2.3 & 39 & 0.15 \\
Central Europe [19] & 0.050 & 400 & 4 & 2.3 & 35 & 0.09 \\
$\begin{array}{c}\text { Umbria-Marche Apennines, } \\
\text { Italy [17] }\end{array}$ & 0.040 & 130 & 4 & 2.3 & 43 & 0.33 \\
$\begin{array}{c}\text { British Columbia [14] } \\
\text { Generic Rock [15] }\end{array}$ & 0.011 & 380 & 4 & 3.0 & 121 & 0.32 \\
California [12] & $0.035-0.040$ & 204 & 4 & 2.4 & $42-48$ & $0.20-0.23$ \\
& 0.040 & 204 & 4 & 2.4 & 42 & 0.20 \\
\hline
\end{tabular}


Table 2: Databases of $Q_{0}$ and $\kappa$ values shown in Figures 1 and 2.

\begin{tabular}{|c|c|c|c|c|}
\hline & $V_{s, 0.03}(\mathrm{~km} / \mathrm{s})$ & $V_{u c}(\mathrm{~km} / \mathrm{s})$ & $Q_{0}$ & $\kappa(\mathrm{s})$ \\
\hline Central and Eastern & 2.8 & 3.3 & 1000 & 0.003 \\
\hline \multirow[t]{4}{*}{ North America } & 2.8 & 3.3 & 900 & 0.003 \\
\hline & 2.8 & 3.3 & 755 & 0.004 \\
\hline & 2.8 & 3.3 & 670 & 0.004 \\
\hline & 2.8 & 3.3 & 500 & 0.006 \\
\hline \multirow[t]{3}{*}{ Western North America } & 0.7 & 2.0 & 150 & 0.066 \\
\hline & 0.65 & 1.8 & 150 & 0.073 \\
\hline & 0.7 & 2.0 & 110 & 0.069 \\
\hline Sino-Korean & 1.2 & 2.7 & 342 & 0.022 \\
\hline \multirow[t]{3}{*}{ Paraplatform } & 1.2 & 2.7 & 189 & 0.039 \\
\hline & 1.2 & 2.7 & 293 & 0.025 \\
\hline & 1.2 & 2.7 & 400 & 0.019 \\
\hline South China Fold & 1.5 & 2.9 & 482 & 0.014 \\
\hline \multirow[t]{3}{*}{ System } & 1.5 & 2.9 & 370 & 0.018 \\
\hline & 1.5 & 2.9 & 256 & 0.027 \\
\hline & 1.5 & 2.9 & 240 & 0.028 \\
\hline \multirow[t]{4}{*}{ Australia } & 2.4 & 3.25 & 500 & 0.012 \\
\hline & 0.65 & 2.2 & 50 & 0.045 \\
\hline & 0.65 & 2.5 & 200 & 0.040 \\
\hline & 2.35 & 3.2 & 550 & 0.011 \\
\hline Southern Iberia & 0.48 & 1.9 & 150 & 0.069 \\
\hline NE Japan & 0.53 & 1.75 & 47 & 0.067 \\
\hline Taiwan & 0.48 & 1.65 & 149 & 0.081 \\
\hline Generic Hard Rock & 2.8 & 3.3 & 680 & 0 \\
\hline Generic Rock & 0.85 & 2.4 & 204 & $0.035-0.040$ \\
\hline Apennines, Italy & 0.62 & 2.3 & 100 & 0.070 \\
\hline Northeastern Italy & 0.62 & 2.3 & 260 & 0.045 \\
\hline Apennines, Italy & 0.62 & 2.3 & 130 & - \\
\hline Southern California & 0.7 & 2.0 & 180 & 0.056 \\
\hline Iceland & 0.65 & 2.4 & - & 0.040 \\
\hline \multirow[t]{3}{*}{ NEHRP Site Class C } & 0.7 & - & - & 0.048 \\
\hline & 1.0 & - & - & 0.04 \\
\hline & 0.74 & - & - & 0.05 \\
\hline Eastern North America & 2.8 & 3.3 & - & 0.006 \\
\hline
\end{tabular}


Table 3: Upper-crust attenuation parameter $\kappa$ for the four prevalent geological formations and regional average for Hong Kong

\begin{tabular}{ccc}
\hline Rock Types & $V_{u c}(\mathrm{~km} / \mathrm{s})$ & $\kappa$ [Equation (6a) \\
\hline Granitic & 2.56 & 0.032 \\
Volcanic & 2.73 & 0.024 \\
Heavily-jointed Volcanic & 2.49 & 0.036 \\
Meta-sedimentary & 2.40 & 0.040 \\
Regional Average & 2.62 & 0.030 \\
\hline
\end{tabular}

Table 4: Upper-crust attenuation parameter $\kappa$ for Melbourne Metropolitan Region

\begin{tabular}{cccc}
\hline$V_{s, 0.03}(\mathrm{~km} / \mathrm{s})$ & $\kappa[$ Equation $(6 \mathrm{a})]$ & $V_{u c}(\mathrm{~km} / \mathrm{s})$ & $\kappa$ [Equation $(6 \mathrm{~b})]$ \\
\hline 1.1 & 0.033 & 2.67 & 0.027 \\
\hline
\end{tabular}




\section{FIGURE CAPTIONS}

Figure 1: Relationship between $Q_{0}$ and shear wave velocity $(S W V)$ from global data

(a) Relationship between $Q_{0}$ and $V_{u c}$

(b) Relationship between $Q_{0}$ and $V_{s, 0.03}$

Figure 2: Relationship between $\kappa$ and shear wave velocity $(S W V)$ from global data

(a) Relationship between $\kappa$ and $V_{u c}$

(b) Relationship between $\kappa$ and $V_{s, 0.03}$

Figure 3: Crustal shear wave velocity ( $S W V$ ) profile models for Hong Kong (Ref.[4])

Figure 4: Crustal shear wave velocity $(S W V)$ profile models for Melbourne

Metropolitan Region (Ref.[41]) 


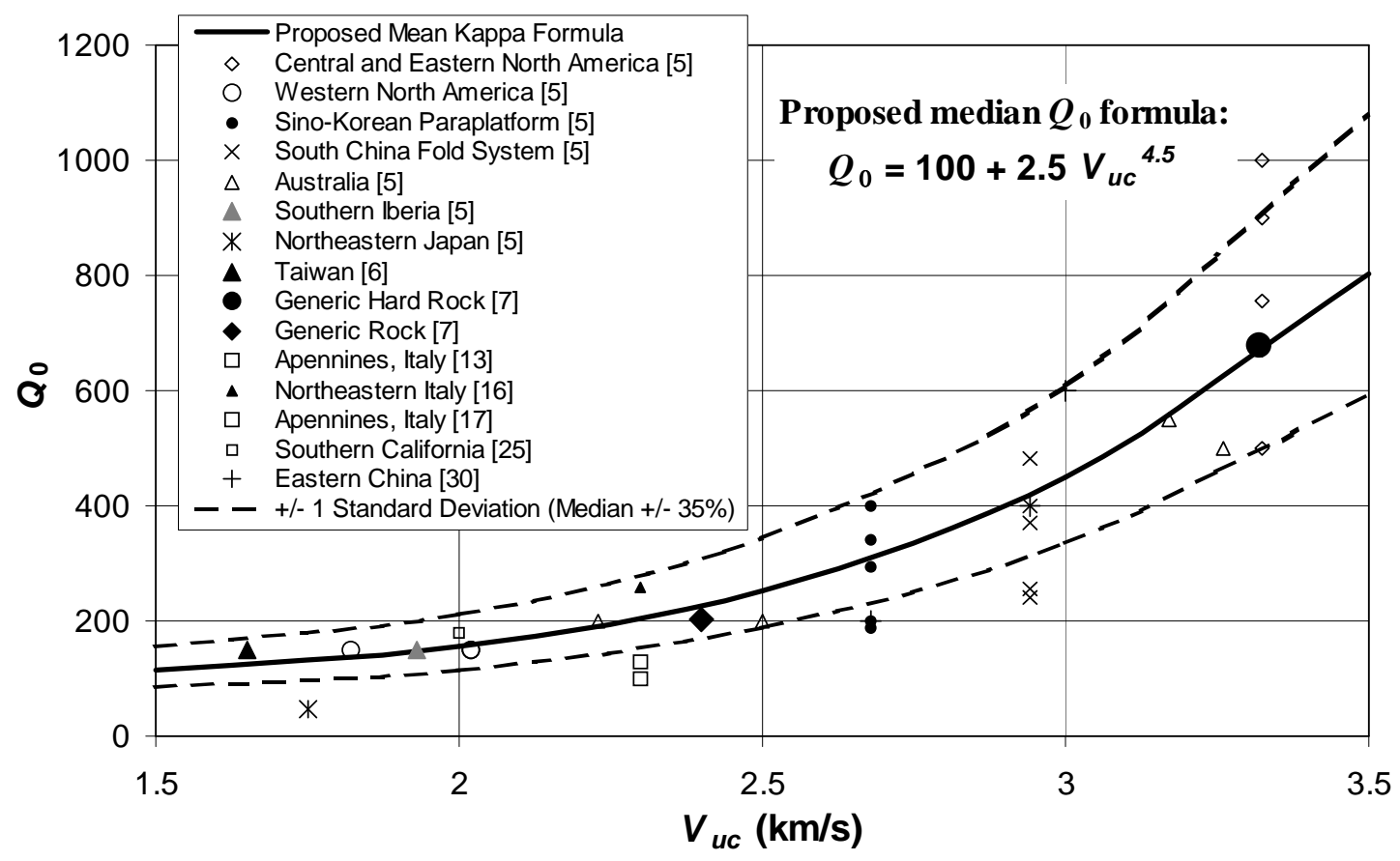

(a) Relationship between $Q_{0}$ and $V_{u c}$

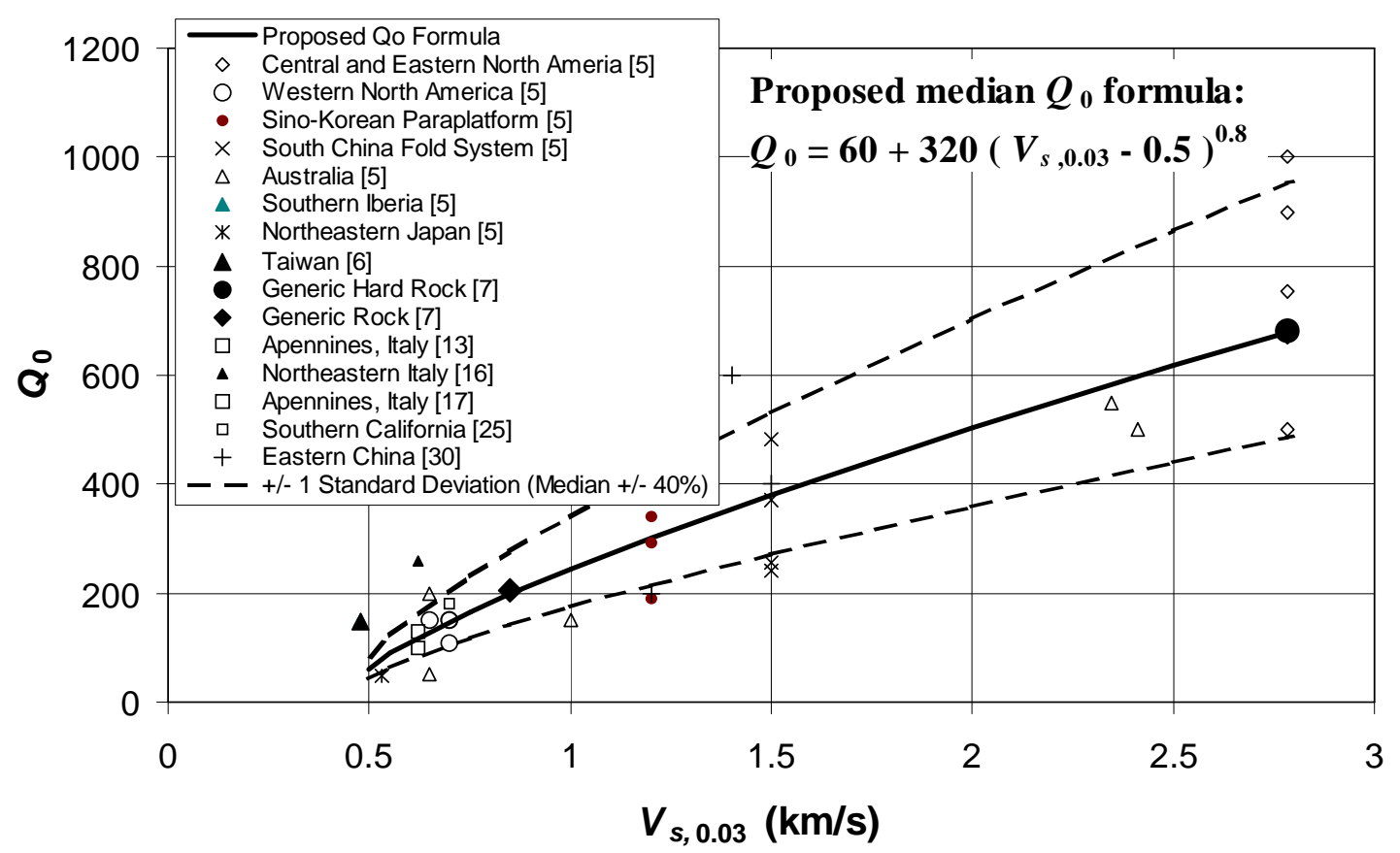

(b) Relationship between $Q_{0}$ and $V_{s, 0.03}$

Figure 1: Relationship between $Q_{0}$ and shear wave velocity $(S W V)$ from global data 


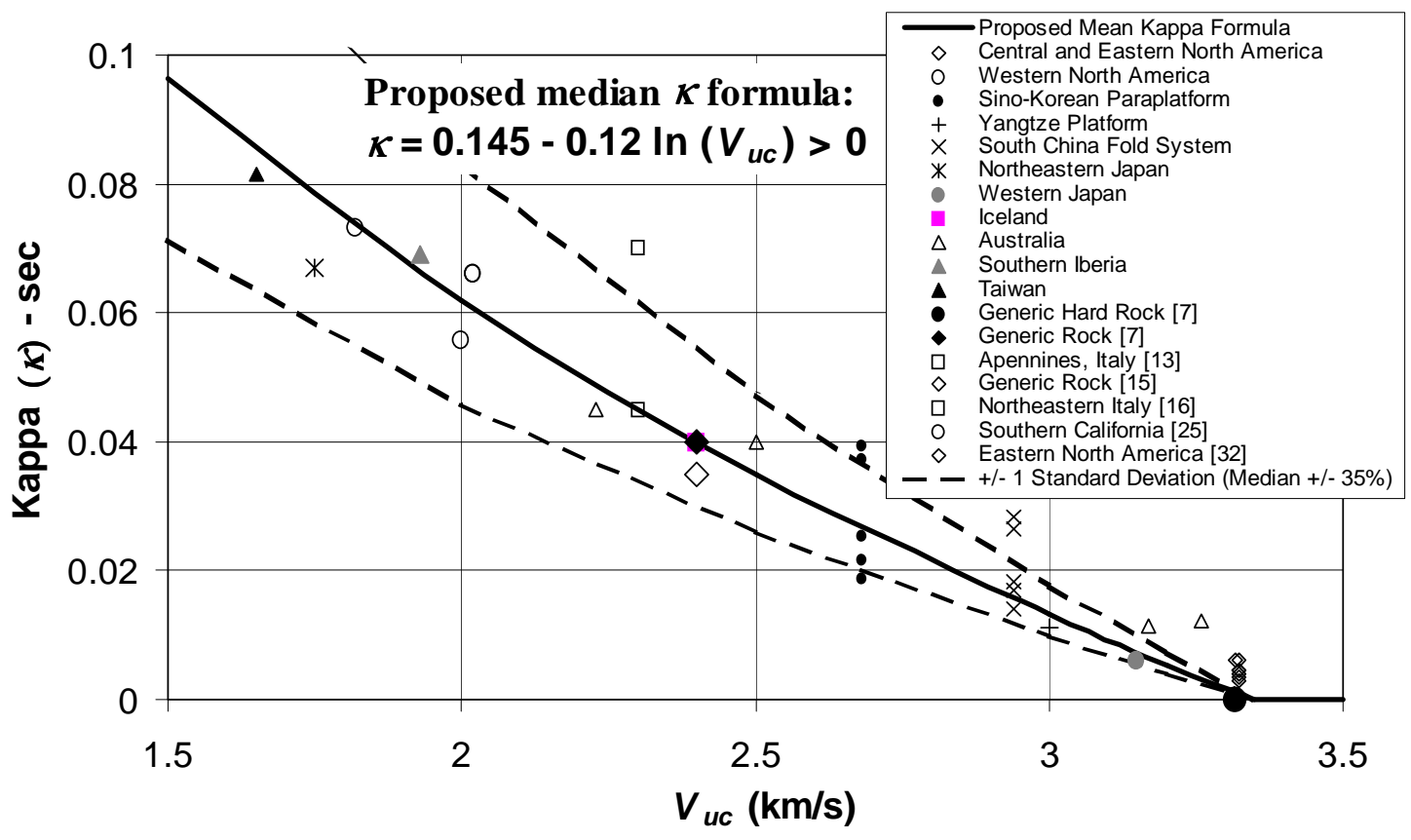

(a) Relationship between $\kappa$ and $V_{u c}$

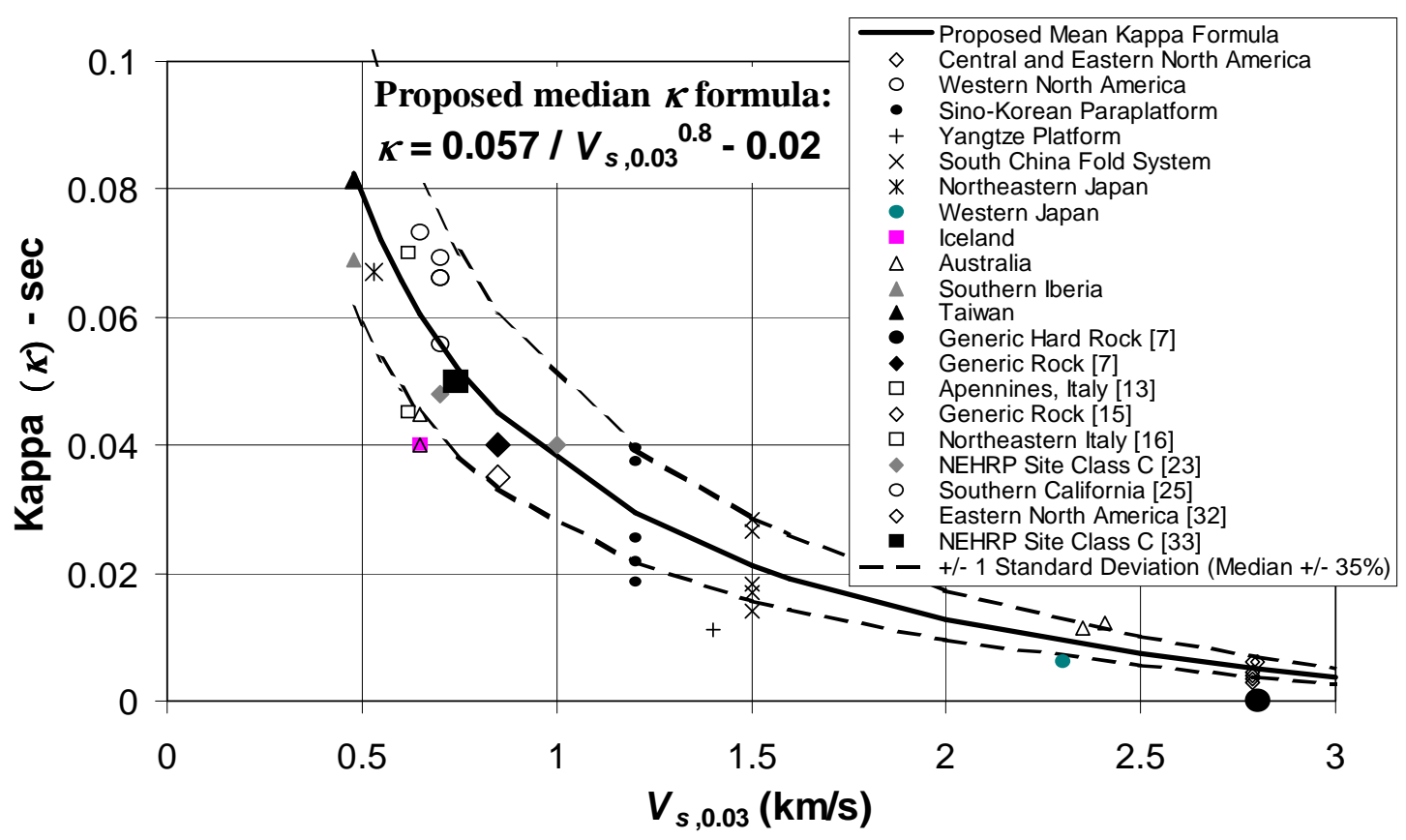

(b) Relationship between $\kappa$ and $V_{s, 0.03}$

Figure 2: Relationship between $\kappa$ and shear wave velocity $(S W V)$ from global data 


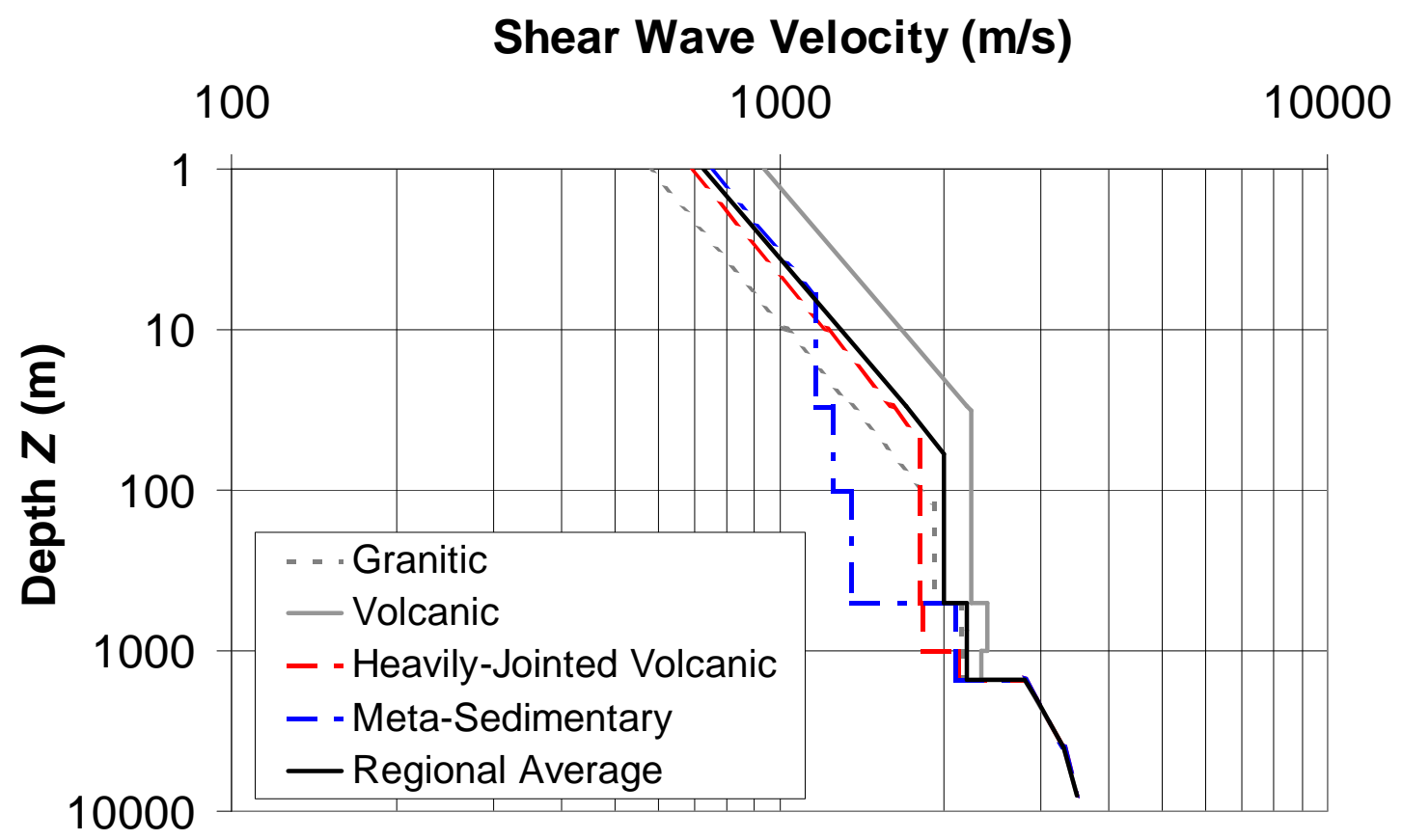

Figure 3: Crustal shear wave velocity ( $S W V$ ) profile models for Hong Kong (Ref.[4]) 


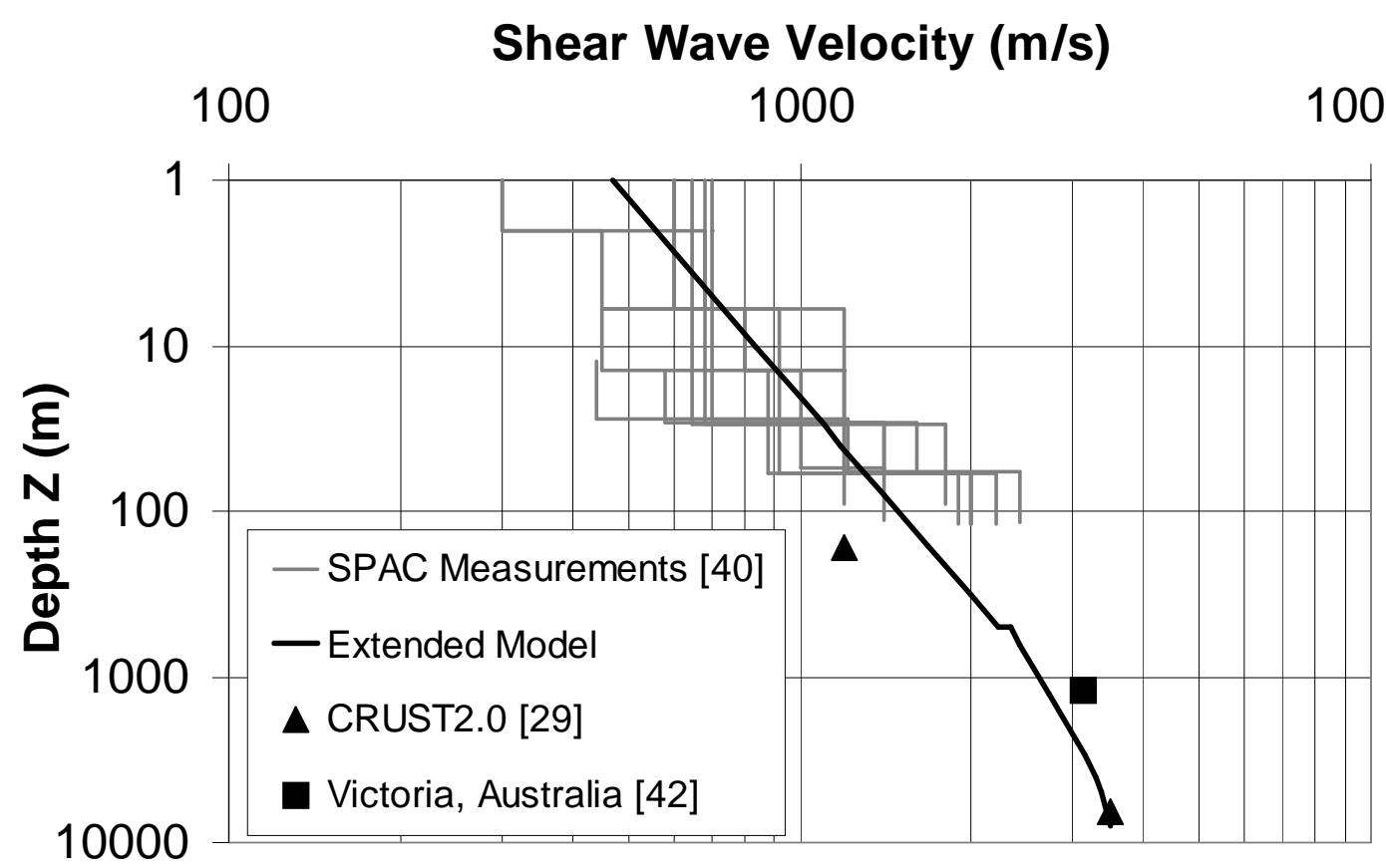

Figure 4: Crustal shear wave velocity $(S W V)$ profile models for Melbourne Metropolitan Region (Ref.[41]) 